UDK: 624.012.4.059

DOI: https://doi.org/10.24867/05CG02Jakovljevic

\title{
PROCENA STANJA, SANACIJA I REVITALIZACIJA ČEŠKOG MAGACINA U NOVOM SADU
}

\section{ASSESSMENT, REPAIR AND REVITALISATION OF CZECH WAREHOUSE IN NOVI SAD}

\author{
Milica Jakovljević, Fakultet tehničkih nauka, Novi Sad
}

\begin{abstract}
Oblast - GRAĐEVINARSTVO
Kratak sadržaj - U radu je dat istorijat, lokacija $i$ tehnički opis Češkog magacina na kom je izvršen detaljan vizuelni pregled kako bi se utvrdio stepen oštećenja koja su se pojavila tokom vremena. Izvršena je procena stanja objekta i predložene su mere sanacije na osnovu uvida $u$ pravila uređenja i građenja na spomeniku kulture koja su propisana važećim planskim dokumentom.
\end{abstract}

Ključne reči: procena stanja, sanacija, Češki magacin

\begin{abstract}
This paper presents history, location and technical description of the Czech warehouse where a detailed visual inspection was carried out to determine a degree of damage which have appeared during service life. Assessment of the condition of the building was made and repair measures are proposed based on insight into a rules of design and construction of the cultural monument which are prescribed by a valid planning document.
\end{abstract}

Keywords: assessment, repair, Czech warehouse

\section{UVOD}

Rad se sastoji iz dva dela, teorijskog i stručnog dela. U prvom delu rada je obrađen teorijski deo u vezi sa sanacijom drvenih konstrukcija u građevinarstvu. Date su metode sanacije i ojačanja drvenih konstrukcija koje se primenjuju nakon pojave različitih vrsta oštećenja ili koje prethode promeni namene objekta.

Prikazane su i intervencije na drvenim konstrukcijama radi osiguravanja objekta pri seizmičkim dejstvima, kao i metode za sprečavanje širenja štetočina $u$ drvenim elementima. Stručni deo rada obuhvata istorijat Češkog magacina sa tehničkim opisom, detaljan vizuelni pregled na osnovu kog je utvrđen stepen oštećenja koja su se pojavila na objektu. Doneti su zaključci o stanju objekta i predložene su mere sanacije na osnovu pravila uređenja i građenja koja su propisana Planom detaljne regulacije Kineske četvrti sa Češkim magacinom u Novom Sadu.

\section{SANACIJA DRVENIH KONSTRUKCIJA U GRAĐEVINARSTVU}

Drvo u građevinarstvu koristilo se još od davnih vremena kao lako dostupan i lako obradiv materijal.

\section{NAPOMENA:}

Ovaj rad proistekao je iz master rada čiji mentor je bila dr Mirjana Malešev, redovni profesor.
Deterioraciju drvenih konstrukcija kroz vremenski period uzrokuju uticaji iz spoljašnje sredine. Drvo je veoma osetljivo na dejstvo i promenu vlage koja izaziva pojavu oštećenja. Takođe, mora se obratiti pažnja na pravilno projektovanje kako ne bi došlo do prekoračenja napona $\mathrm{u}$ drvenim konstrukcijama, kao i na izbor drvene građe, njenu adekvatnu obradu i skladištenje zbog moguće pojave defekata $u$ građi koji na različite načine utiču na upotebljivost drvnog proizvoda i ekonomičnost primene.

Metode sanacije drvenih elemenata su:

- Sanacija zamenom elemenata, kojom se najčešće saniraju drveni elementi iznad krovne konstrukcije. Element se zamenjuje od oslonca do oslonca, a veze sa drugim elementima se ostvaruju projektovanjem i izvođenjem odgovarajućih veznih elemenata i spojnih sredstava za drvene konstrukcije.

- Sanacija oslonaca drvenih greda oblaganjem talpama sa strane ili valjanim profilima, ili ,TRS“ sistemom (Slika 1) koji podrazumeva privremeno podupiranje konstrukcije i isecanje oštećenog mesta umesto kog se dodaje novi oslonački deo koji se povezuje sa gredom tradicionalnim vezama ili lepljenjem dva dela sa ojačanjima od čelika ili „fiberglasa“. Takođe, moguće je oštećene drvene grede podupreti drvenim ili čeličnim profilima na mestima oslanjanja, kako bi se povećala nosivost grede smanjenjem raspona.

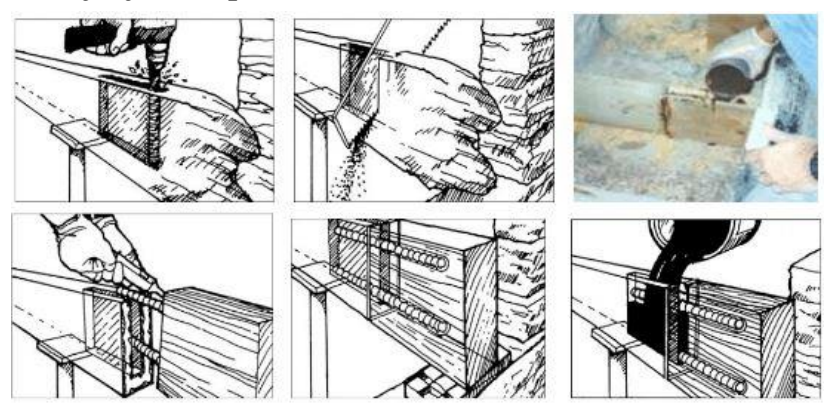

Slika 1. ,TRS“ sistem [1]

- Sanacija površinskih oštećenja na drvenim gredama injektiranjem sa smešom od epoksi smola, uz prethodno uklanjanje oštećenog dela.

- Sanacija prslina i pukotina drvenih elemenata zapunjavanjem epoksidnim malterima ukoliko su pukotine širine veće od $5 \mathrm{~mm}$ i utezanjem preseka staklenim, karbonskim vlaknima ili čeličnim šipkama tanjeg profila uz primenu epoksidnog lepka ukoliko je 
dubina pukotine veća od $30 \%$ poprečnog preseka. Prsline širine manje od $5 \mathrm{~mm}$ se ispunjavaju epoksidnim lepkom.

- Metode za sprečavanje širenja štetočina mogu biti fizičke (vruć zrak, mikrotalasi, površinsko sagoravanje), kao i hemijske (otrovni gasovi, tečna sredstva za impregnaciju, kapsula sa otrovom za teže dostupne delove konstrukcije).

- Sanacija poprečnog preseka ojačanjem čeličnim profilima ili drvenim elementima.

- Ostvarenje veza između zidova i tavanica, odnosno zidova i krova čeličnim sponama ili trnovima, radi osiguranja objekta pri seizmičkim dejstvima.

- Sanacija konstrukcije sprezanjem drveta i betona kako bi se povećala savojna čvrstoća i krutost tavanice, kao i seizmička otpornost objekta.

- Sanacija konstrukcije dodavanjem novih konstrukcijskih elemenata za neke slučajeve oštećenja objekta, promene namene ili preopterećenja.

- Sanacija drvene konstrukcije postavljanjem armature u kvadratne žlebove koji moraju imati dimenzije veće od armature za najmanje $2 \mathrm{~mm}$. Veza između armature i drveta se ostvaruje zalivanjem žlebova epoksidnom smolom.

\section{3. ČEŠKI MAGACIN U NOVOM SADU}

\subsection{Istorija Češkog magacina}

„Češki magacin“ (Slika 2) je industrijski objekat izgrađen 1921. godine u jugoistočnom delu Novog Sada, uz samu obalu Dunava. Podigla ga je Češka država za potrebe skladištenja poljoprivrednih proizvoda koji su kupovani u gradu i okolini, a potom Dunavom transportovani na sever. Godine 2001. on je utvrđen za spomenik kulture, a po svojim arhitektonskim karakteristikama spada u grupu najvrednijih industrijskih objekata sačuvanih na teritoriji Novog Sada i ima veliki značaj za proučavanje istorije privrednih objekata sa teritorije grada.

Češki magacin se nalazi u ulici Bulevar despota Stefana 7, na katastarskoj parceli broj 7333/4 KO Novi Sad II.

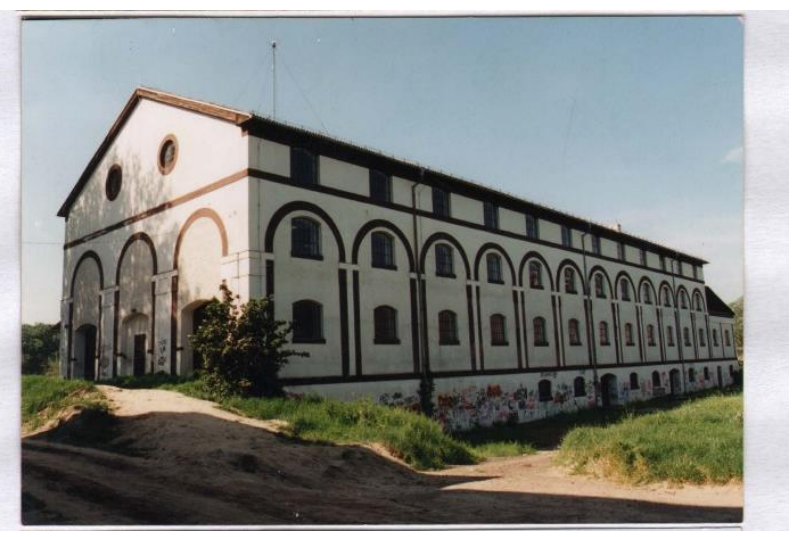

Slika 2. Češki magacin [2]

\subsection{Tehnički opis}

Češki magacin ima pravougaonu osnovu dimenzija $61.2 \mathrm{~m}$ x $19.8 \mathrm{~m}$ sa podrumskim prostorom, prizemljem i dva sprata, a na zapadnoj strani se nalazi aneksni prizemni deo objekta sa podrumom, pravougaone osnove dimenzija 10.0m x 19.8m. Visina slemena višeg dela objekta iznosi $18.8 \mathrm{~m}$, dok je aneksni deo visine $11.5 \mathrm{~m}$, mereno od poda suterena. Objekat ima naglašeno dugačke podužne fasade sa dvanaest vertikala otvora. $\mathrm{Na}$ istočnoj, bočnoj fasadi su tri portala i dva okulusa, dok je uz zapadnu istovremeno dozidan parterni aneks sa krovom na jednu vodu. $\mathrm{Na}$ južnoj, glavnoj fasadi, nalaze se četiri monumentalna dvokrilna portala i pokriven drveni trem.

Konstruktivni sistem Češkog magacina je kombinacija masivnog sistema sa skeletnim.

Zidovi od opeke su izgrađeni bez ukrućenja horizontalnim i vertikalnim serklažima i postavljeni su u poprečnom i podužnom pravcu.

Međuspratne tavanice su izrađene od tavanjača koje se oslanjaju na noseće zidove i čelične grede koje preko čeličnih, a na nekim mestima i drvenih i zidanih, stubova i nosećih zidova prenose opterećenje $u$ donje delove objekta. Izuzetak je međuspratna tavanica prizemlja $\mathrm{u}$ dograđenom aneknom delu objekta koja je pruski svod.

Krovna konstrukcija u višem delu objekta je drvena vešaljka u kombinaciji sa dvostrukom stolicom. U objektu manje visine krov je jednovodan.

U sredini enterijera objekta je pravougaoni prostor za dizalicu-teretni lift koji je oivičen gvozdenim profilima i mat staklom. Unutar objekta pored oba poduzna zida nalazi se po jedno jednokrako čelično/drveno stepeniše koje je obezbeđeno čeličnom ogradom.

Na Slici 3 prikazan je poprečni presek objekta.

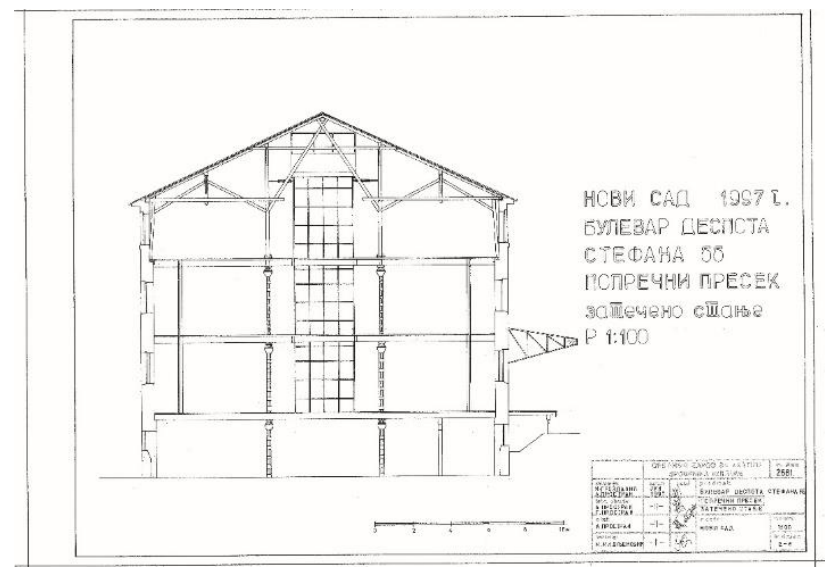

Slika 3. Poprečni presek objekta [3]

\section{PROCENA STANJA OBJEKTA}

Urađen je detaljan vizuelni pregled, gde je uključeno snimanje položaja i veličine oštećenja. Obuhvaćeni su dostupni delovi unutrašnjih i spoljašnjih nosećih zidova, međuspratna konstrukcija sa čeličnim i stubovima od opeke i drveta, krovna konstrukcija, stepenište i teretni lift.

Oštećenja u vidu otpadanja maltera i fasadne boje, nastala usled kristalizacije soli, se nalaze u suterenskim delovima zidova koji su najviše izloženi delovanju podzemne vode sa rastvorenim solima.

Delovi zidova u blizini krovnog pokrivača i oštećenih olučnih vertikala su upili atmosfersku vlagu, a usled dejstva mraza su nastala oštećenja na njima $u$ vidu 
otpadanja maltera i boje na fasadi, pukotina u malteru i krunjenja maltera na ivicama zida.

Zbog vlažne sredine, na zidovima se pojavila buđ, mrlje od vlage, gljivice, mahovina i biološko rastinje (Slika 4.), a usled padavina mrlje od slivanja vode preko zaprljane fasade.

$\mathrm{Na}$ temenima lukova iznad prozorskih otvora su se pojavile pukotine koje se pružaju kroz maltersku spojnicu (Slika 5).

Usled mehaničkih dejstava nastale su rupe u zidu, podužna oštećenja zbog vađenja instalacija, a vidljive su rupe na fasadi na mestima gde su se oslanjale drvene grede drvenog platoa. $\mathrm{Na}$ delu unutrašnjeg zida je pomerena i ispala opeka iz svog položaja.

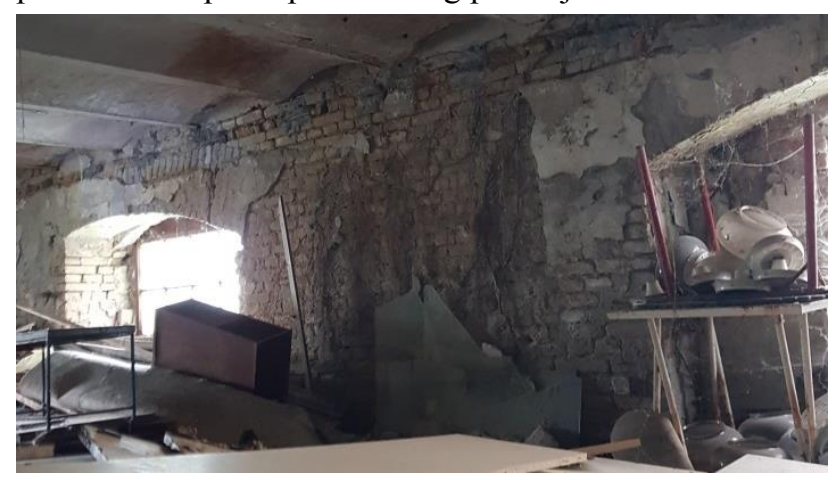

Slika 4. Biološko rastinje u zidu [4]

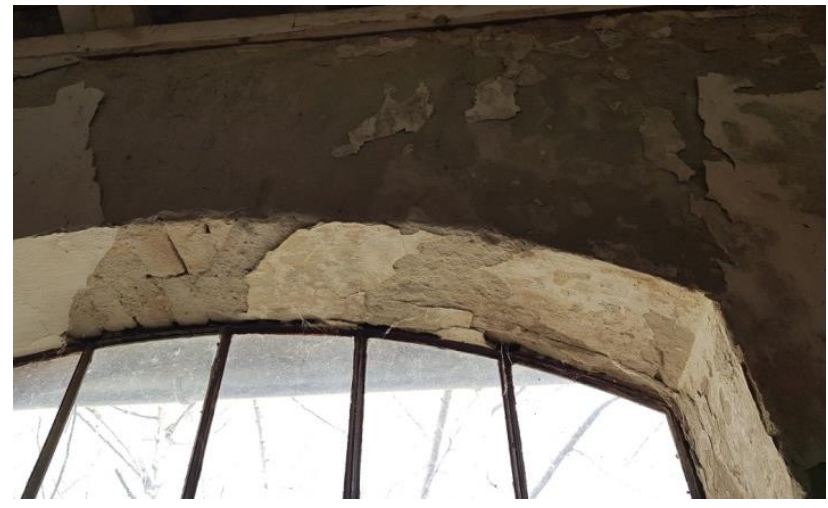

Slika 5. Pukotina u zidanom luku [5]

$\mathrm{Na}$ međuspratnim drvenim konstrukcijama došlo je do pojave podužnih pukotina na tavanjačama (Slika 6) i drvenim gredama koje ih nose usled rasušivanja drvene građe. Pojavile su se mrlja od vlage, buđ i truljenje na osloncima tavanjača. Vidljive su rupe od insekata na tavanjačama između suterena i prizemlja. Na mestu na kom je vršeno dodatno oslanjanje drvenih tavanjača, došlo je do pada jednog kraja drvene grede.

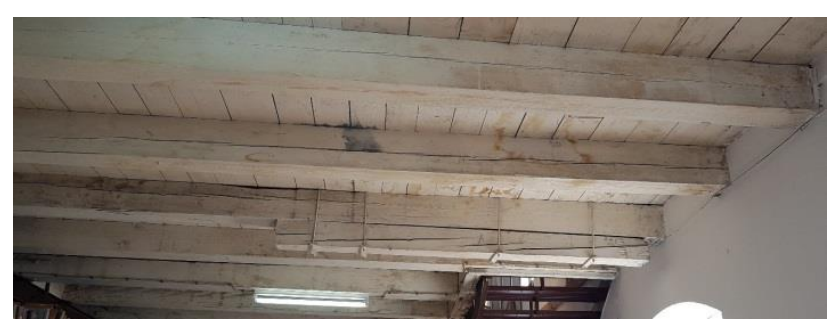

Slika 6. Podužne pukotine na tavanjačama [6]

Na pruskom svodu su vidljive mrlje od vlage, korozija čeličnih nosača, mrlje od korozije čelika, kao i ljuskanje i otpadanje mlatera. Na delovima zidanog svoda je vidljiva opeka.

U drvenim stubovima i kratkim elementima u suterenu su vidljive vertikalne pukotine usled rasušivanja drvene građe, a čelični stubovi su korodirali zbog direktne izloženosti podzemnim vodama.

Propuštanje krovnog pokrivača uzrokovalo je oštećenja na krovnoj konstrukciji (Slika 7) koja se javljaju u vidu mrlja od vlage, buđi, truljenja i otpadanja delova venčanice. Vidljive su i podužne pukotine na krovnoj konstrukciji.

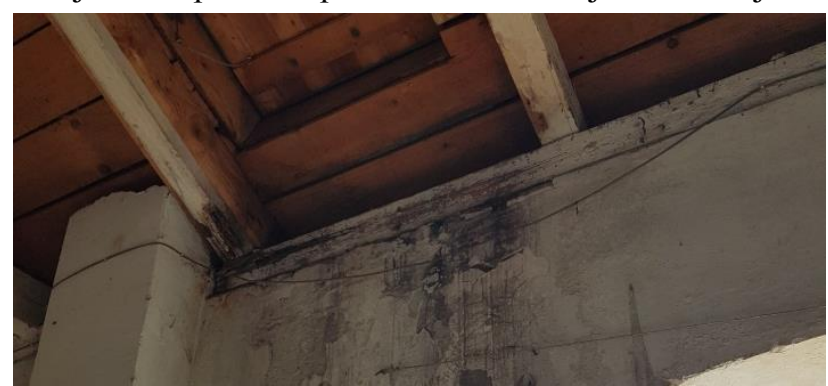

Slika 7. Buđ i truljenje venčanice i roga [7]

Čelični materijal teretnog lifta je korodirao u suterenu objekta. Drvena gazišta i drveni čeoni delovi stepeništa su promenili boju usled dejstva vlage, a na čeličnim gazištima je došlo do ljuskanja boje.

\section{ZAKLJUČAK O STANJU OBJEKTA}

Na osnovu vizuelnog pregleda Češkog magacina utvrđeno je sledeće stanje:

- Nosivost zidova nije ugrožena, ali redukovana je nosivost lukova iznad otvora u zidu;

- Nosivost međuspratnih konstrukcija je smanjena zbog pojave podužnih pukotina i truljenja u oslonačkim delovima tavanjača;

- Nosivost krovne konstrukcije je smanjena zbog podužnih pukotina koje se nalaze na stubovima;

- Stabilnost objekta nije narušena;

- Funkcionalnost objekta je delimično narušena;

- Trajnost objekta je ugrožena.

\section{MERE SANACIJE OBJEKTA}

Nakon uvida u Plan detaljne regulacije Kineske četvrti sa Češkim magacinom u Novom Sadu, utvrđena je planirana promena namene objekta Češkog magacina u prostor za kulturu, muzej sa pratećim delatnostima i društveni aktivizam. U skladu sa adaptiranjem prostora za planiranu namenu, kao i sa očuvanjem izvornog stanja konstrukcije bez radova koji mogu ugroziti statičku stabilnost spomenika kulture, predložene su mere sanacije objekta koje obuhvataju postupak konzervacije.

\subsection{Predložene konstruktivne mere sanacije nosećih zidova}

- Injektiranje pukotina u zidu epoksidnim smolama;

- Sanacija zidova vađenjem opeke i zamena sa novom ili stavljanje nove opeke na mestima gde ona fali; 


\subsection{Predložene nekonstruktivne mere sanacije nosećih zidova}

- Obijanje trošnog maltera i nanošenje novog produžnog maltera;

- Izrada horizontalne hidroizolacije tehnikom presecanja zidova pod nazivom HIO-tehnologija;

- Izrada vertikalne hidroizolacije kondor trakama;

- Izrada termoizolacije na unutrašnjoj strani zida na prizemlju i spratovima na osnovu proračuna koeficijenta prolaza toplote i difuzije vodene pare kroz zid (Slika 8);

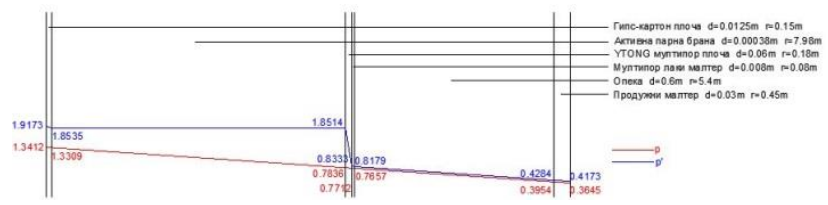

Slika 8. Difuzija vodene pare kroz zid [8]

- Izrada termoizolacije na unutrašnjoj strani zida i izvođenje poda u suterenu (Slika 9) na osnovu proračuna koeficijenta prolaza toplote.

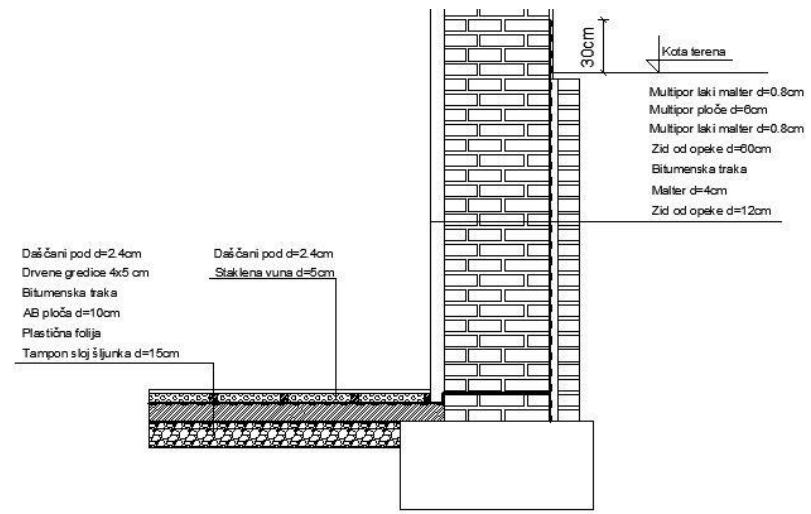

Slika 9. Presek poda i nosećeg zida u suterenu [9]

\subsection{Predložene konstruktivne mere sanacije krovne konstrukcije}

- Sanacija trulih venčanica njihovom zamenom ili injektiranjem smešom na bazi epoksi smola;

- Sanacija prslina i pukotina zapunjavanjem epoksidnim malterom i utezanjem, ili pri širini pukotina manjih od $5 \mathrm{~mm}$ sanacija se vrši ubrizgavanjem epoksidnog lepka;

\subsection{Predložene nekonstruktivne mere sanacije}

- Izolacija krovne konstrukcije iznad krovnih rogova na osnovu proračuna koeficijenta prolaza toplote i difuzije vodene pare kroz slojeve iznad krovne konstrukcije. Predložena je zamena oštećenih delova krovnog pokrivača.

\subsection{Predložene konstruktivne mere sanacije međuspratnih konstrukcija}

- Zamena oslonačkih delova tavanjača „TRS“ sistemom;

- Popunjavanje pukotina na drvenim tavanjačama/zamena tavanjača;

\subsection{Predložene nekonstruktivne mere sanacije međuspratne konstrukcije}

- Čišćenje korozije nosača pruskog svoda i nanošenje antikorozione zaštite. Zamena maltera pruskog svoda;

- Čišćenje čeličnih stubova i greda u suterenskom delu objekta i nanošenje antikorozione zaštite;
- Uklanjanje drvenih greda i stubova koji nose međuspratnu tavanicu između suterena i prizemlja;

\subsection{Ostale konstruktivne mere sanacije}

- Seizmičko ukrućenje objekata utezanjem zidova pomoću čeličnih zatega i povezivanje drvenih tavanica sa nosećim zidovima pomoću čeličnih elemenata;

\subsection{Ostale nekonstruktivne mere sanacije}

- Izvođenje novih olučnih instalacija;

- Postavljanje aluminijumskih prozora.

\section{ZAKLJUČAK}

$\mathrm{Na}$ osnovu vizuelnog pregleda utvrđeno je da nostivost $\mathrm{i}$ stabilnost celokupnog objekta nije narušena, međutim trajnost objekta je ugrožena, a funkcionalnost je delimično narušena. Ukoliko kapilarna i atvosferska vlaga budu i dalje dospevale na objekat, mraz i kristalizacija soli će uzrokovati degradaciju nosećih zidova. Takođe, drvena međuspratna konstrukcija bi nastavila da upija vlagu sa zidova, a truljenje oslonaca bi se povećavalo i na taj način bi bila ugrožena nosivost drvene tavanice. Oštećenja elemenata krovne konstrukcije bi se povećala usled dejstva atmosferskih padavina koje prolaze kroz oštećeni krovni pokrivač, a to bi smanjilo nosivost krovne konstrukcije.

Objekat danas zadovoljava kriterijume nosivosti i stabilnosti, ali u budućem periodu oštećenja na objektu bi mogla to ugroziti ukoliko se ne preduzmu odgovarajuće mere zaštite.

\section{LITERATURA}

[1] Tatjana Kočetov Mišulić, Drvene konstrukcije, Skripta sa predavanja, Fakultet tehničkih nauka, Novi Sad 2017. 2018.

[2] Tatjana Kočetov Mišulić, Oštećenja i sanacija drvenih konstrukcija, Skripta sa pedavanja, Fakultet tehničkih nauka, Novi Sad 2009/2010, 2010/2011, 2011/2012.

[3] Amir Čaušević i Nerman Rustempašić, ,, Rekonstrukcije zidanih objekata visokogradnje “, Sarajevo 2014.

[4] Opštinski zavod za zaštitu spomenika kulture Novi Sad, Predlog odluke o utvrđivanju industrijskog objekta „Češki magacin" na Bulevaru despota Stefana broj 7 u Novom Sadu za spomenik kulture, Novi Sad oktobar 1998.

[4] Plan detaljne regulacije Kineske četvrti sa Češkim magacinom u Novom Sadu (,Službeni list Grada Novog Sada“, broj 17/17)

[5] Mirjana Malešev i Vlastimir Radonjanin, Oštećenja sanacija zidanih konstrukcija, Skripta sa predavanja, Fakultet tehničkih nauka, Novi Sad

\section{Kratka biografija:}

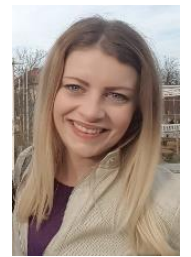

Milica Jakovljević, rođena je u Bačkoj Topoli, Republika Srbija, 1992. god. Master rad na Fakultetu tehničkih nauka iz oblasti Građevinarstva - Konstrukcije odbranila je 2019.god.

kontakt: jakovljevic.milica@ outlook.com 